Sección I: Estudios 



\title{
LA PRIMERA UNIVERSIDAD DEL CARIBE COLOMBIANO, UN MODELO ILUSTRADO PARA AMÉRICA COLONIAL
}

\author{
Diana SOTO ARANGO ${ }^{1}$ \\ Universidad Pedagógica y Tecnológica de Colombia
}

\begin{abstract}
RESUMEN: El trabajo se propone analizar el proceso de organización y aprobación del Colegiouniversidad de San Pedro Apóstol que se aprobó por Cédula Real en 1806, en la Villa de Mompox. Se demostrará como esta institución presenta la característica de tener una Constitución de carácter Ilustrado que fue elaborada por Eloy Valenzuela. Por otra parte, la aprobación, por parte del Rey, del nuevo colegio-universidad dependió de la influencia política de don Pedro Pinillos y del dinero que le dio éste a la Corona Española.

El artículo se fundamenta en la metodología de la historia social de la educación basada en fuentes primarias, fundamentalmente, del Archivo General de la Nación. Colombia (AGN). y el Archivo General de Indias de España. (AGI).
\end{abstract}

PALABRAS CLAVE: Universidad colonial; reformas universitarias; constituciones; Caribe colombiano, Ilustración.

ABSTRACT: This work pretends to analyze the organization process and the approving of the school-University of Sant Peter Apostle that was approved by the Real Order in 1806 in the Ville de Mompox. It is going to demonstrated how that institution presents the characteristic of having an Enlightenment Constitution. It was made by Eloy Valenzuela. On the other hand, the approving, by the King the new school-university depended of the political influence of Dn. Pedro Pinillos and the money gave to the Spanish crown. This paper is based on the history education methodology, documented in primary sources of the "Archivo General de la Nación" in Colombia and the "Archivo General de Indias".

KEY WORDS: Colonial University, University Caribbean Colombian, Enlightenment reforms.

\section{INTRODUCCIÓN}

El desarrollo educativo-cultural del Caribe en el virreinato de la Nueva Granada $^{2}$ no se puede analizar sin estudiar el desarrollo económico de la Provincia

${ }^{1}$ Dra. Diana Soto Arango. Profesora Titular, Universidad Pedagógica y Tecnológica de Colombia y del Doctorado en Ciencias de la Educación, RudeColombia. Coordinadora Grupo: "Historia de la Universidad Latinoamericana". HISUlA. Código Colciencias COL0011868. 
de Mompox. En especial, implica el análisis de varios factores desde: la excelente ubicación geográfica, la elite comerciante momposina con la rivalidad cartagenera y la incidencia del grupo de la Expedición Botánica en la Villa de Santa Cruz de Mompox.

Por lo anterior, la gran pregunta que nos hacemos es de ¿Cuáles fueron los factores que incidieron para que en la Villa de Mompox se estableciera ColegioUniversidad con aprobación Real en 1806 y por qué esta situación no se dio en Cartagena principal epicentro de desarrollo en el Caribe de la Nueva Granada? Ésta gran pregunta estará presente en la perspectiva de análisis que daremos a conocer en este trabajo. Las fuentes se localizan principalmente en el Archivo General de la Nación de Colombia, Archivo General de Indias (AGI), en el periódico La Voz de Mompox y luego en bibliografía secundaria.

\section{EL COLEGIO-UNIVERSIDAD DE SAN PEDRO APÓSTOL: UN PRODUCTO DE LA BONANZA COMERCIAL DE LA VILLA DE MOMPOX Y DE LA INCIDENCIA DEL GRUPO DE LA EXPEDICIÓN BOTÁNICA'}

En nuestro análisis caracterizamos tres elementos que incidieron en ese hecho de transformación cultural en la Villa de Mompox.

En primera instancia, señalamos que el desarrollo cultural y social de la villa de Santa Cruz de Mompox $^{3}$ está unido al desarrollo económico de la misma y al enfrentamiento político-comercial que se daba con la ciudad de Cartagena. Sin lugar a dudas el epicentro era Cartagena, pero Mompox creada sólo cuatro años después en 1537 se convirtió pronto en la segunda ciudad del Caribe en población y movimiento económico-comercial.

\footnotetext{
${ }^{2}$ Los primeros virreinatos fueron los de Nueva España y del Perú en 1542. El de Nueva Granada se crea en 1711, se suprime en 1723 y se crea definitivamente en 1739. En 1768 se creó el Virreinato de Buenos Aires. Los primeros virreinatos fueron los de Nueva España y del Perú en 1542. El de Nueva Granada se crea en 1711, se suprime en 1723 y se crea definitivamente en 1739. En 1768 se creó el Virreinato de Buenos Aires. Brito FigueroA, F. (1987). Historia económica y social de Venezuela. Caracas: Universidad Central de Venezuela, tomo 111, p. 1 203. ReSTREPO, J. M. (1974). Historia de la Revolución en Colombia, Medellín: Editorial Bedout, pp. 48-49. OCAMPO LóPEZ, J. (1984). Historia básica de Colombia, Bogotá: Plaza \& Janes, pp. 126-127.

${ }^{3}$ La Villa de Santacruz de Mompox fue fundada por Pedro de Heredia en 1537 con la categoría de puerto fluvial. Cartagena se había fundado en 1533. Se le consideró Provincia separada de Cartagena por Real Cédula del 3 de agosto de 1774. Pero la misma se revocó en 1777 por la influencia de la elite de Cartagena. En adelante señalaremos sólo como la villa de Mompox.
} 
Por lo anterior, se incluye en el análisis el hecho significativo que en el censo de población de $1780^{4}$, en la Provincia de Cartagena, la segunda ciudad más poblada era la villa ${ }^{5}$ de Santacruz de Mompox con 7.093 habitantes mientras Cartagena tenía 13.387 y la capital Santa Fe con 24.000. Lo relevante es que Mompox después de Cartagena tenía el mayor número de esclavos (837) pero presentaba un escaso número de indios que sólo llegaban a 77. En la categoría de personas libres alcanzaba el número de 5.248 donde es posible esté concentrado el mayor número de comerciantes en mestizos y mulatos. Sin embargo, en el estrato blanco ${ }^{6}$ Mompox ocupaba el tercer lugar (878) después de Cartagena y Lorica. Para nuestro análisis lo significativo se localiza en una fuerte elite criolla comercial que se había educado a finales del siglo XVIII en la capital santafereña.

Hay un aspecto que conviene señalar en la fundación del Colegio-Universidad y es el del desarrollo de la villa de Mompox para entender el auge educativo de comienzos del siglo XIX en esta villa. En este caso, como señala Georges Duby, la ciudad se caracteriza por "rasgos particulares de status jurídico, de sociabilidad y de cultura. El papel no es económico es político"7. Sin embargo, en las "últimas décadas coloniales el concepto de urbanización empezó a significar progreso de las ciudades y pueblos, reestructuración financiera, mejoramiento de los servicios

${ }^{4}$ El censo de 1780 presenta en Cartagena la siguiente distribución:

\begin{tabular}{cllllll}
\hline Ciudad & Eclesiásticos & Blancos & Indios & Libres & Esclavos & Total \\
\hline Cartagena & 223 & 3.389 & 56 & 7.612 & 2.107 & 13.387 \\
Mompox & 53 & 878 & 77 & 5.248 & 837 & 7.093 \\
\hline
\end{tabular}

Fuente. "Padrón de la Provincia de Cartagena. Año de 1780", en Archivo General de la Nación de Colombia. Sección Colecciones. Fondo Ortega Ricaurte. Censos 1, Caja 37, Documento 11.

${ }^{5}$ La clasificación de los núcleos poblacionales según Wolfe es: Caserío: de 20 a 200 habitantes; Caserío Grande: de 200 a 1.000 habitantes; Villorrio de 1.000 a 2.500; Pueblo de 2.500 a 10.000 ; Ciudad de más de 10.000 habitantes". Véase en VArgas Lesmes, J. (1989). Historia de Bogotá. Conquista y Colonia. Bogotá: Salvat Villegas Editores, tomo II, p. 46.

${ }^{6}$ En el análisis que realiza Humboldt de la población americana de 1800 a 1825 establece que la población total de las colonias españolas en América era de 16.785.000 almas, con 13.509.000 gentes de color indios mestizos, negro y mulatos y 3.276 blancos. De estos españoles nacidos en la metrópoli eran 150.000. El porcentaje de blancos en la América española era del 19\% mientras en Estados Unidos era del $60 \%$. MingueT, Ch. (1985). Alejandro de Humboltd historiador y geógrafo de la América española. México: Universidad Nacional Autónoma de México, p.237

${ }^{7}$ Citado por Conde Calderón, J. (1999). Espacio, sociedad y conflictos en la Provincia de Cartagena. 1740-1815. Barranquilla: Fondo de Publicaciones de la Universidad del Atlántico, p. 16. 
urbanos y mayor control de la moralidad y del comportamiento de sus habitantes". 8 Este ideal de progreso para Mompox lo personificó a finales del siglo XVIII don Pedro Pinillos.

Hay que decir, que en las colonias españolas las ciudades tenían una finalidad en relación a "privilegiar los intercambios con la metrópoli lejana". 9 Por este motivo considera Conde que la villa de Mompox se creó "en la banda izquierda del río Magdalena, límite natural de las gobernaciones de Cartagena y Santa Marta"10. Ahora bien, el puerto fluvial de Mompox sobre el río Magdalena se convirtió en el centro administrativo de los pueblos del bajo Magdalena y además se constituyó en el "centro de equilibrio entre los comerciantes y terratenientes y entre los antiguos y los nuevos pobladores quienes competían por la propiedad de la tierra y de los hatos" ${ }^{11}$. Como hemos visto, reiteramos que la villa de Mompox ${ }^{12}$, a finales del siglo XVIII, se caracterizó por el intenso comercio y por ser uno de los puertos más importantes sobre el río Magdalena. Era el sitio obligado para los mercaderes procedentes de Cartagena, Santa Marta y Riohacha y para los que venían del centro del país a través de Honda. Allí se concentraba el comercio de esclavos, el del oro, con el de las mercancías de telas y productos vegetales como la quina y el tabaco. Se describe a Mompox a comienzos de 1810 como una villa de "14.000 habitantes, tres escuelas primarias, la nueva universidad, un clero numeroso e ilustrado [...] y era esta villa el gran mercado de oro y otros productos del país, y el gran depósito de donde los pueblos del interior se proveían de mercancías europeas"13.

${ }^{8}$ GARRIDO, M. (1993). Reclamos y representaciones. Bogotá, Banco de la República, p.203. Cita a Morse.

${ }^{9}$ Conde Calderón, J. (1999). Op.Cit., p. 16.

10 "Era admitido que una villa se podía fundar con sólo 10 colonos y unos ocho cargos administrativos". CONDE CALDERÓN, J. (1999). Op.cit., p. 16.

${ }^{11}$ GARRIDO, M. (1993). Op. cit., pp. 207-208.

${ }^{12}$ La villa de Santa Cruz de Mompox la fundó don Alonso de Heredia el día 3 de mayo de 1537. Esta villa está localizada al norte del país y fue en la época uno de los principales puertos fluviales sobre el río Magdalena de obligado tránsito hacia la capital del Virreinato. La Corona española en reconocimiento de su "espíritu emprendedor, a su crecimiento y desarrollo económico y cultural le dio el título de villa". Carlos III en 1774 la erigió en provincia autónoma. Posteriormente, es una de las primeras ciudades que firma el Acta de Independencia lo hace el 6 de agosto de 1810. Don Manuel Rodríguez Torices, mediante decreto del 3 de noviembre de 1812, la declara Benemérita de la Patria y le da el título de valerosa. La ley 163 de 1959 declara la ciudad Monumento Nacional.

13 Bibliografía consultada: Anales Del Estado De Bolívar, (s/f). Estadística de Mompox.Boletines Historiales de la Academia de Historia de Santa Cruz de Mompox.-FALS BORDA, O.(1979). Mompox y Loba. Bogotá, Carlos Valencia.-Fernández De PiÑEREZ, M. (1967). Unas vidas 
No es extraño, por lo tanto, que en 1784 se solicitara la creación del Consulado de Mompox con su director Gonzalo José de Hoyos y que en este mismo año se fundará en esta villa la primera Sociedad de Amigos del País de América colonial. No cabe duda que en estos aspectos marcó el liderazgo la villa de Mompox frente al desarrollo que llevaba Cartagena. En concreto, Cartagena trató de fundar en 1787 una Sociedad Económica con la denominación de Sociedad de Amigos del País de Turbaco, para apoyar el cultivo del algodón sin lograrlo, como lo señala Pedro Fermín de Vargas (1986) ${ }^{14}$ y sólo consiguió el Consulado en 1795. Por el contrario, debemos indicar que la Sociedad de Amigos del País de Mompox "creó corresponsales y apoderados en todo el Reino con el apoyo del virrey Caballero y Góngora". ${ }^{15}$ Además, se nombró miembro de honor al sabio Mutis quien estaba unido a esta ciudad por ser el sitio de residencia de su hermano y también porque había estado en la misma desde su llegada al Virreinato en 1762 y posteriormente también se había desplazado a la Villa a realizar un estudio sobre el terreno y el cambio de lugar del cementerio ${ }^{16}$.

En definitiva, esta comparación final sirve para aclarar que la Villa de Mompox era un centro comercial de relevancia en el virreinato y en la costa Caribe con nexos y apoyos en la capital. Sólo resta decir que el contrabando se había convertido en una línea comercial de mayor flujo económico. Pero antes de

novelescas y un sacrificio glorioso. Mompox, Tipografía el Esfuerzo. GutiérRez De PiÑerez, E. (s/f). La fundación de Mompox. Mompox.-PeÑAS Galindo, D.(1987). Efémeris de Mompox. Cartagena: Espitía Impresores.- IBID. (1981). La independencia y la mafia colonial. Bogotá: Tercer Mundo. Salcedo Del Villar. P. (1939). Apuntaciones historiales de Mompox. Cartagena: Gobernación del Departamento de Bolívar, primera edición, p. 15.

${ }^{14}$ Pedro Fermín de Vargas nació en San Gil en 1762 y murió en Londres posiblemente en 1812. Se educó en el Colegio Mayor del Rosario. Ocupó varios cargos públicos entre otros, Oficial Primero de la Secretaria del Virreinato. En 1784 se vinculó a la Expedición Botánica. Publicó un ensayo sobre el "Guaco" en Papel Periódico de Santa Fe. En 1788 Mutis le encargó recoger la quina para la exportación. En 1789 se le nombró Corregidor y Juez de residencia. En 1790 escribió "Pensamientos políticos y la Memoria sobre la Población" de Zipaquirá. En 1791 se fuga de Bogotá abandona su mujer y se va con una mujer casada. Viaja a EE.UU., Las Antillas, Francia e Inglaterra. Se relaciona con Francisco Miranda. Realiza varios escritos y representaciones al gobierno inglés. López Méndez informa de su muerte en una carta en febrero de 1811. Fermín De VARGAS, P. (1986). Pensamientos Políticos. Bogotá: Nueva Biblioteca Colombiana de Cultura. Procultura, p. 64.

${ }^{15}$ El 7 de agosto de 1784 se creó la Sociedad con el director perpetuo el coronel don Gonzalo Josef de Hoyos. El 19 de septiembre del mismo año se dictaron los Estatutos de la Sociedad. Salcedo Del Villar, P. (1987). Apuntaciones historiales de Mompox. Cartagena: Edición conmemorativa de los 450 años. Comité hijos de Mompox, Gobernación Departamento de Bolívar, p.16.

${ }^{16}$ La Voz de Mompox, mayo 21 de 1932, no 17. 
terminar, un tema que nos lleva a una gran pregunta es ¿qué factores incidieron para que esta villa apartada en el continente americano se convirtiera en pionera de una de las Instituciones de la Ilustración como era: Las Sociedades Económicas de Amigos del País? Porque si bien es cierto que la villa de Mompox era relevante para nuestro virreinato por las características señaladas anteriormente de ello no se deduce una importancia en el conjunto de la colonia española en América. Es bien sabido que el virreinato de la Nueva Granda, a comienzos del siglo XIX, ${ }^{17}$ sólo exportaba dos millones de pesos en productos agrícolas y tres millones en oro y plata. E importaba en mercancías 5.700 .000 pesos. Esta importación y exportación era irrelevante si la comparamos con el virreinato de Nueva España que importaba veintidós millones y exportaba 31.500 .000 o en el Virreinato del Perú que importaba 11.500 .000 y exportaba 12 millones. ${ }^{18}$ No es este el lugar adecuado para analizar las cifras económicas pero es relevante señalar que para 1804 el producto bruto de las colonias americanas era de 36 a 38 millones ${ }^{19}$ de pesos mientras el de la metrópoli era inferior con la suma de 35 millones.

Un segundo aspecto, que contribuye a explicar la organización de la universidad en la vVilla de Mompox se refiere al hecho de localizar en esta ciudad al comerciante español Pedro Martínez Pinillos(1748-1809) ${ }^{20}$ quien llegó a la villa en

${ }^{17}$ Las importaciones y las exportaciones crecieron a partir del Decreto de Libre comercio de la metrópoli y de sus colonias en 1778. En 1778 se exportaba en agricultura 3.728 .000 pesos y en 1785 se ascendió a 19.415.000. Se importaba en 1778 en mercancías 2.314 .000 pesos y en 1785 se ascendió a 21.499.000. MingueT, Ch. (1985). Alejandro de Humboldt historiador y geógrafo de la América española. México: Universidad Nacional Autónoma de México, p. 338.

18

El virreinato de menor desarrollo económico era el de Buenos Aires. Importaba 3.500.000 pesos en mercancías y exportaba igual que el virreinato de Nueva Granada. No deja de ser significativo que la Capitanía de Caracas importaba casi igual al virreinato de la Nueva Granada. Sus importaciones eran de 5.500.000 pesos. MingUet, Ch. (1985). Alejandro de Humboldt historiador y geógrafo de la América española, tomo II. Ciudad del México: Universidad Nacional Autónoma de México, 1985. p. 336.

${ }^{19}$ De este valor correspondía a Nueva España el valor de 20 millones y a Nueva Granada tan sólo 3.8 y a Caracas 1.8. Ibidem, tomo II, p. 342.

${ }^{20}$ Pedro Julián Martínez de Pinillos de Nájera nació 8 enero de 1748 en Torrecillas, provincia de Burgos, en la actualidad denominada de la Rioja. Llegó a Cartagena en 1767 y se dedicó al comercio. En 1770 se estableció en Mompox donde vivió casi 39 años (1770-1809). Tuvo el privilegio por la Corona española de ser el único importador de mercancías para esta villa. Desempeñó los cargos más importantes en Mompox. Entre otros: Comisario de Barrio de Mompox (1778-1780); Mayordomo de Propios y rentas en 1782; participó en la Sociedad de Amigos del País que se fundó 12 de sept. de 1784; Mayordomo de la Cofradía del Santísimo Sacramento. Le donó 6 casas y obtuvo del Rey Carlos IV que la elevaran al rango de Archicofradía mediante Real Cédula del 29 de diciembre de 1800; en 1784 viaja a España y establece mayor comercio con Barcelona; Alcalde del Segundo Voto 
1770 y permaneció en la misma por casi 39 años (1770-1809). Es importante señalar que desde comienzos del siglo XVIII se había superado la resistencia de los españoles y criollos en considerar el comercio un oficio vil. Por el contrario, ahora los comerciantes eran un sector determinante y con influencias en la Corte por las donaciones que realizaban al Rey. En efecto, para esta época el español comerciante Pedro Pinillos tenía un reconocimiento y prestigio en la Corona y el virreinato. Según se ha podido establecer, fue significativo, el privilegio que le otorgó la Corona española para ser el único importador de mercancías para esta villa y por Real Orden, del 2 de noviembre de 1792, se le eximió del pagó de impuestos por la importación y exportación de productos a la metrópoli ${ }^{21}$. Como es de suponer esta situación de privilegio le permitió ocupar y comprar los cargos más distintivos de la Villa. Podemos señalar el de Regidor Alcalde Mayor Provincial de la villa de Mompox por el valor de 400 pesos a finales de 1787. Pero lo fundamental es que siempre cumplió con las donaciones puntuales para el Rey. Así por ejemplo, lo vemos donando 6 casas para obtener del rey Carlos IV la Real Cédula, del 29 de diciembre de 1800, que elevara de rango la cofradía de Mompox. En este punto es importante indicar que las cofradías se convirtieron en un medio de estrechar vínculos comerciales. Así pues, retomando el hilo conductor de las donaciones de don Pedro Pinillos, que posiblemente incidió en las peticiones que realizaba a la Corte, no cabe duda que el hecho de donar 5.000 pesos en 1802 para apoyar al rey en su guerra contra Francia e Inglaterra le hizo ganar puntos en su petición de aprobación real para el Colegio-Universidad de Mompox.

Ahora bien, otro aspecto singular se enmarca dentro del proceso de secularización de la educación superior que había iniciado el fiscal Francisco Moreno y Escandón en la ciudad de Santa Fe en 1768. En este sentido el citado colegio-universidad para la villa de Mompox tenía como objetivo formar a la población civil y se establecía que el patronato fuera real administrado a través del

de Mompox el 24 de diciembre de 1786; Alcalde de la Hermandad de la Villa de Mompox en 1787; compró el cargo de Oficio de Regidor Alcalde Mayor Provincial de la Villa de Mompox por el valor de 400 pesos a finales de 1787. Solicitó la jubilación y se la otorgó el Rey el 5 de julio de 1794; Diputado de Mompox ante el Consulado de Comercio de Cartagena el 17 de marzo de 1796 no aceptó el cargo y el Rey lo exoneró mediante Cédula del 18 de nov de 1796. Contrajo matrimonio con su prima, criolla, Manuela Tomasa de Nájera y Segura (1750-1825) el 12 de mayo de 1775. Se destaca que recibió pérdidas por los corsarios ingleses $(1795,1796,1797)$. Por otra parte, fueron significativas las donaciones que le dio al Rey en la guerra contra Francia e Inglaterra: 5.000 pesos en 1802.

21 Zambrano Arias, A. y Miranda De Leon P. (1999). Don Pedro Martínez de Pinillos en Mompox. Sincelejo: Compugraficas, p. 27. 
Ayuntamiento de la Villa ${ }^{22}$. Conocemos que en la villa de Mompox la educación estuvo sin mayor desarrollo y hasta 1767 las expectativas educativas las cubría el Colegio de San Carlos de la Compañía de Jesús que fundaron en $1644^{23}$. Pero es bien conocido que con la expulsión de los jesuitas en 1767 la elite criolla quedó en esta región sin ningún centro educativo para educar a sus hijos. Es por ello que, se iniciaron las clases con tutores pero no existía un centro educativo que acreditara esta educación particular.

En realidad, era una necesidad vital la organización de un centro educativo que evitará el desplazamiento de los jóvenes a la capital. Hemos localizado que en el sólo Colegio de San Bartolomé se presentó un número considerable de matrícula de alumnos provenientes de la villa de Mompox en la década de los años 70. Por ejemplo en el año 1778 se matricularon $20^{24}$. Así pues, el mayor problema de otorgar una educación superior a los hijos de la elite de la villa era de difícil solución.

Como señalamos, al inicio, nuestro interés se centra en entender las condiciones socio-políticas que dan origen al Colegio de San Pedro Apóstol y en especial al carácter Ilustrado ${ }^{25}$ del mismo. No podemos dejar de lado que se requería de un mecenas que donará el dinero para la fundación y por otra unas Constituciones avaladas por el virrey que no cayeran en la burocracia administrativa de la Corte. Es bien conocido que todas las reformas Ilustradas que se enviaron a la Corte nunca regresaron con el aval real a las colonias americanas. Planteadas así las cosas, hay que decir, que el español Pedro Martínez Pinillos logró con los apoyos del Cabildo en Mompox, del virrey de Nueva Granada y sus contactos en la Corte que se expidiera Cédula real para la fundación del Colegio-Universidad de San Pedro-Apóstol en la

22 "El Ayuntamiento aceptó el patronato e hizo publicar por bando la Real Cédula del 10 de enero de 1806". Anales del Estado de Bolívar (s/f), "Estadística de Mompox”, p.137-148.

${ }^{23}$ El 25 de abril de 1643 los jesuitas compraron el solar e iniciaron la construcción de la casa para el Colegio y el convento de la comunidad.

${ }^{24}$ En la lista que se revisó se localizó la siguiente información: 1770: 3; 1774: 3; 1775: 15; 1776: 12; 1777: 15; 1778: 20; 1779: 13 "Lista de estudiantes matriculados en el Colegio de San Bartolomé". Archivo General de la Nación, Fondo Colegio San Bartolomé, Libro 11.

${ }^{25}$ Soto Arango, D. y UriBE, J. T. (2002): "La Ilustración en el virreinato de la Nueva Granada", en Universidad e Ilustración en América. Nuevas perspectivas, Edición Coordinada por María Cristina Vera. Universidad de Córdoba. Córdoba: Argentina, Universidad Nacional de Córdoba, pp. 131-158. Soto ARANGO, D. (1988). "La ilustración española y la reformas educativas en el Virreinato de la Nueva Granada", en Historia de la Relaciones Educativas entre España y América. V Coloquio Nacional de Historia de la Educaciòn, Sevilla, Universidad de Sevilla, pp. 57-67. 
villa de Mompox constituyéndose en un modelo de institución Ilustrada para toda América colonial.

Llama la atención que el trámite de la solicitud de fundación del colegiouniversidad tenía sus apoyos en la Corte porque no deja de ser significativa la rapidez con la que se expide la Real Cédula si se tiene en cuenta la lentitud administrativa de la época. ${ }^{26}$ La Real Cédula le concedió al Colegio el privilegio de otorgar grados al establecerla como universidad. Decía la Real Cédula:

"Visto todo lo referido a mi Consejo de Indias con lo que informó su contaduría general... he venido en acoger bajo mi soberana protección y aprobar las dichas fundaciones y en mandar se erija en universidad el referido colegio, con las mismas facultades y prerrogativas que el de esa capital, vistiendo sus colegiales igual beca con el escudo de su titular San Pedro y facultad de conferir en ella los grados en las facultades que se cursen en la misma universidad". ${ }^{27}$

Retomando el concepto de "progreso de las ciudades y pueblos" en la villa de Mompox lo lideró don Pedro Pinillos a finales del siglo XVIII. Se le ha reconocido por la reconstrucción y donaciones a los templos de Mompox. Por ejemplo, al templo de San Agustín le realizó donaciones por 40.000 pesos. ${ }^{28}$ Fundó el hospicio, enladrilló la calle de la Contaduría, dio donaciones a la cárcel. En 1793 con el incendio y en 1803 con el desbordamiento del río Magdalena se encargó de recuperación de la gente y de sus casas. El 31 de octubre de 1801 compró a la Real Hacienda Española la Casa Colegio de los Jesuitas. Allí instaló el hospicio, el hospital de Jesús y el Colegio de San Pedro. Al año siguiente, en 1802, destinó 176.500 pesos $^{29}$ para la creación de dos escuelas de primeras letras en los barrios San Francisco y Santa Bárbara.

${ }^{26}$ El 3 de abril de 1803, el Virrey Mendinueta solicitó al monarca Carlos IV la aprobación de esta fundación. El Consejo de Indias la aprobó el 27 de julio de 1804 y se otorgó la Real Cédula el 10 de noviembre de 1804. Esta Real Cédula aprobó igualmente el Hospicio-hospital del Corazón de Jesús. Salcedo Del Villar, P. (1987): p. 79. Gusto. La Voz de Mompox. (1932): "Constituciones de la Universidad". Mompox, nº 19 del 4 de junio de 1932.

${ }^{27}$ Ibídem., p. 113.

28 Zambrano Arias A. y Miranda De Leon, P. (1999). Don Pedro Martínez de Pinillos en Mompox. Sincelejo: Compugráficas, p. 29-33.

29 Además se agregaba los intereses que producía anualmente este capital al $5 \%$ anual que ascendía a 3.380 pesos. 
Debemos indicar que el citado Colegio inició estudios con 6 becas en 1802. Se enseñaba latinidad, filosofía y teología. Por lo anterior, no es de extrañar que posteriormente luego de inaugurada la universidad, el 29 y 30 de agosto de 1809, a escasos cinco meses empezará a otorgar grados. En concreto, en el mes de enero de 1810 se inicia el proceso de graduación a los estudiantes en la nueva Universidad. La única explicación que tenemos es el hecho de haber validado los estudios del antiguo colegio. El primer grado que se otorgó fue el de Bachiller en Filosofía al estudiante Eugenio de la Torre y Corral el 17 de enero de 1810. Pero luego, el 19 de enero se lo expiden a Tomás Germán Ribón en la misma área. Pero en octubre de ese año se expiden grados en Bachiller y licenciados en Teología y Cánones. Es más, se otorgó grado de doctor en Teología y Derecho Canónico a tres estudiantes $^{30}$.

Hasta ahora se ha comentado de las condiciones socio-políticas que originaron el hecho de crear universidad en la villa de Mompox. Pero hay que subrayar que esta universidad se creó con unas Constituciones y un Plan de Estudios de los más avanzados que se plantearon en América colonial. Ciertamente, el tercer aspecto, al cual nos referimos al comienzo de este trabajo se relaciona a la influencia del grupo de la Expedición Botánica`en la creación del Colegio-Universidad de Mompox.

\section{EL COLEGIO-UNIVERSIDAD DE SAN PEDRO APÓSTOL UN PROYECTO DE UN GRUPO ILUSTRADO EN LOS ALBORES DE LA NUEVA REPÚBLICA}

Hemos comentado dos condiciones especiales para la fundación del ColegioUniversidad. Pero además, lo que se debe resaltar es que la propuesta fue una de las más avanzadas en las colonias americanas que logró aprobación real y aplicación por un corto período de tiempo.

Es significativo, en primera instancia, destacar la incidencia de José Celestino Mutis $(1732-1808)^{31}$ en este proyecto educativo. El gaditano había llegado al

${ }^{30}$ Zambrano Arias, A. y Miranda De LeOn P. (1999): Ibídem., pp.62, 63.

31 José Celestino Mutis nace en Cádiz el 16 de abril de 1732 y muere en Santa Fe de Bogotá el 11 de septiembre de 1808. Recibió los grados de bachiller en filosofía en 1753 y de bachiller en medicina en 1757 en la universidad de Sevilla aunque la práctica la realizó en Cádiz.. En Madrid obtuvo el título de médico en el Real Proto-medicato. Desde junio de 1757 hasta finales de julio de 1760 estudió en el Jardín Botánico del Soto de Migas Calientes bajo la dirección de Barnades. Mutis salió de Madrid el 28 de julio de 1760 con destino a Cádiz para embarcarse a Cartagena de Indias el 7 de septiembre de 1760 en calidad de médico del virrey Pedro Messía de la Cerda y Cárcamo. Llegó a 
virreinato en 1760 en calidad de médico del virrey Messia de la Cerda. Como el mismo lo manifiesta los dos primeros años se le fueron en atender a los enfermos de la capital virreinal pero sus intereses eran otros y así se lo manifestó al virrey en las dos representaciones que envío al rey Carlos III para "la realización de la historia natural de América". ${ }^{32}$ Mutis en los citados documentos expresaba el ambicioso proyecto que posteriormente sería la Expedición Botánica. Es imprescindible señalar que estos planteamientos de Mutis serían el feliz comienzo de una nueva etapa en el virreinato. La investigación de la naturaleza americana con la finalidad de "saber y conocer las producciones admirables con las que la divina Providencia ha enriquecido los dilatados dominios que tiene la fortuna de vivir bajo la feliz dominación de vuestra majestad en este nuevo mundo"33. El citado proyecto estaba acompañado de la creación de un gabinete de historia natural que reuniese ejemplares de plantas, objetos y minerales que se encontrasen en el Nuevo Mundo.

No se puede olvidar que es el siglo de las expediciones científicas al nuevo mundo. Francia y Alemania se adelantaban en este proyecto. Pero además, estaba el beneficio económico que podría extraerse de la cochinilla, maderas finas, yerbas bálsamos y otras plantas útiles. Sin embargo, este proyecto sólo se haría realidad 20 años más tarde con la Real Cédula del 1 de noviembre de 1783 bajo el auspicio del Virrey Caballero y Góngora, protector de Mutis.

No es nuestro objetivo realizar un estudio de la Expedición Botánica de Mutis pero diremos que la trascendencia fue copernicana en el virreinato. Alrededor de Mutis se congregó la elite Ilustrada y la influencia repercutió en todo el virreinato. El grave problema que afrontó la expedición era el de personal preparado para realizar las observaciones botánicas. Dentro de este contexto se tiene que ver el Plan de Estudios de Moreno y Escandón para Santa Fe. Pero como es conocido este Plan sólo se aplicó por cinco años. En este sentido la oportunidad se presentó nuevamente cuando don Pedro Pinillos solicita a Mutis que le recomiende a una persona para elaborar las Constituciones del Colegio -Universidad para la villa de Mompox. En este punto se debe recordar que Mutis ya estaba ligado a la villa de Mompox por medio de su hermano que había establecido negocios en esta ciudad. Por este motivo, y por haber estado en la villa durante dos épocas diferentes

Cartagena el 29 de septiembre. En Mompox se encontraba el 8 de enero de 1761 y el 24 de febrero llegó a Santa Fe.

${ }^{32}$ Véase un análisis de este documento en Soto ARANGO, D. (1989). Mutis: filósofo y educador. Bogotá: Universidad Pedagógica Nacional, pp. 87 a 91.

33 Documentos (1983). Mutis y la Expedición Botánica. Bogotá: Ancora Editores, p. 127. 
conocía los intereses y necesidades de la región. Es precisamente, a Mutis a quien le piden que señale el nombre de quien se encargaría de elaborar las Constituciones y Plan de Estudios para la nueva Institución educativa.

Desde luego, era una oportunidad para él y su grupo el poder cristalizar las ideas ilustradas que venían tratando de introducir infructuosamente, de una manera institucional, en la enseñanza de los colegios de la capital. Aún estaba en la palestra la polémica suscitada por la defensa de las teorías de Newton y Copérnico que había realizado el mismo Mutis en el Colegio Mayor del Rosario en 1773. Posteriormente, varios catedráticos siguiendo sus pasos trataron de realizar conclusiones públicas sobre este mismo tema con la consecuencia de haber perdido sus cargos y haber sido amenazados de expulsarlos de la ciudad ${ }^{34}$. La situación no era fácil. Aún más, recientemente en 1801 los agustinos calzados habían requerido del permiso del virrey para poder exponer públicamente en conclusiones públicas el sistema copernicano.

Hay todavía otro aspecto que conviene destacar y es el hecho de formar personal para la Expedición Botánica y era la oportunidad de realizar un estudio botánico en una región que estaba sin influencia directa en los estudios de la Expedición. Es por ello que se requería proponer un nombre que tuviese respeto académico y que no fuese acusado de proponer teorías o ideas en contra de la monarquía. La persona recomendada fue el cura Eloy Valenzuela (1756-1834). ${ }^{35}$

Para entender la propuesta se debe conocer quién era Valenzuela. Pero además, lo significativo es que toda la propuesta ilustrada fue avalada con su firma por Pedro Pinillos y de esta manera salió para el respectivo trámite ante: Cabildo de Mompox, Gobernador, Virrey, Consejo de Indias y finalmente la anhelada Cédula Real.

En efecto, Eloy Valenzuela llega de la mano de Mutis en 1770 al Colegio Mayor del Rosario ${ }^{36}$ del que se hace catedrático de Filosofía en 1777 para explicar

${ }^{34}$ Véase un amplio estudio en Soto ARANGo, D. (1992). Polémicas universitarias en Santafé de Bogotá. Bogotá: Universidad Pedagógica Nacional. ColCIENCIAS

${ }^{35}$ Nace en Girón el 6 de julio de 1756 y muere asesinado en Bucaramanga el 31 de octubre de 1834. En 1766 conoce a José Celestino Mutis en Bucaramanga y en 1770 ingresa como colegial en el Rosario donde fue alumno de Mutis. Soto ArAngo, D.(1989). Mutis: filósofo y educador. Bogotá: Universidad Pedagógica Nacional, p. 35.

36 "Informaciones de don Eloy Valenzuela, para su ingreso en el Colegio Mayor del Rosario", Santa Fe, 20 de octubre de 1770. Archivo Colegio Mayor del Rosario en adelante ACMR, Vol. 119, fls 267 a 270 . 
bajo la Reforma de Moreno y Escandón la nueva filosofía Ilustrada. No fue un azar el hecho que en esta reforma el estudio de las matemáticas se hiciera obligatoria porque se intentó dar una formulación científica al conocimiento, al pretender introducir una nueva enseñanza, cuyos contenidos estaban basados en el conocimiento experimental.

Hay que destacar que el tiempo de docencia de Eloy Valenzuela fue corto ${ }^{37}$ pero impactó por la dedicación a sus estudiantes y los contenidos de sus enseñanzas basados en la física experimental y en Newton que los venía explicando José Celestino $\mathrm{Mutis}^{38}$ en el Colegio Mayor de Rosario. Don Joaquín Escobar, vicerrector del Colegio ${ }^{39}$ del Rosario describe que el catedrático Valenzuela "había cumplido su ministerio con tanta exactitud... que con cuyo tesón logró instruir a sus discípulos en los tratados de lógica crítica, aritmética, álgebra, geometría y secciones cónicas, los que sustento con ellos en dos públicas conclusiones" ${ }^{\$ 0}$.

Hay, sin embargo que mencionar los contenidos de las conclusiones públicas que dirigió el catedrático Valenzuela y los nombres de sus alumnos que luego sobresalieron en la actividad académica de los Colegios y en la política nacional. En el primer año defendió en dominicales con "Ignacio Tejada las preliminares de lógica. Las segundas de aritmética con José Antonio Rota. Las terceras de álgebra con José Antonio Ramón González y dos más con Rota la geometría con González la trigonometría". ${ }^{41}$ En 1778 defendió en las dominicales las siguientes conclusiones públicas: con Pedro Fermín Vargas las preliminares de física; con Fernando Vergara ${ }^{42}$ varios capítulos sobre la naturaleza y atributos del cuerpo en

${ }^{37}$ Inició la cátedra el 19 de octubre de 1777 y la dejó al finalizar el curso en 1778 porque al año siguiente pasa a ocupar el vicerrectorado de este Colegio. El 13 de septiembre de 1777 inicia la reclamación por el salario que se le adeuda del trienio. ACMr, Volumen 125, Libro $1^{\mathrm{o}}$ de Colegiales, fl. 7. y Volumen 124, fl. 178. Biblioteca Nacional de Colombia en adelante BNC, Libros Raros y Curiosos, Instrucción Pública, $n^{\circ} 13531$, fls. 41 y v.

38 Mutis fue catedrático en el Rosario de 1770 a octubre de 1774. Continúo Joaquín Urrutia a quien le correspondió iniciar el nuevo Plan de Estudios de Francisco Moreno Escandón. Soto ARANGO, D.(1989). Op. cit., p. 35.

${ }^{39}$ Santa Fe, 1779. ACMR. Vol. 124, fl. 178.

${ }^{40}$ Santa Fe, 1 de septiembre de 1777. ACMR. Volumen 125, Libro $1^{\circ}$ de Colegiales, fls. 8 a 10. $B N C$, Libros Raros y Curiosos, Instrucción Pública, $\mathrm{n}^{\circ}$ 13531, Sala 1, fl. 40.

${ }^{41}$ ACMR. Volumen 125, Libro $1^{\circ}$ de Colegiales, fl. 8.

42 Fernando Vergara con el apoyo de Mutis dirigió en 1785 una carta al arzobispo-virrey solicitando la reapertura de la cátedra de matemáticas. La cátedra se reabrió el 29 de enero de 1787 con el plan de estudios que había presentado Mutis. Valenzuela fue el catedrático pero Mutis se 
particular, con Juan de la Rocha los elementos de la mecánica en castellano; con Tadeo Cabrera "el sistema newtoniano sobre los colores y la heterogeneidad de la luz"43.

Ya hemos valorado en otros trabajos el éxito del Plan de Estudios de Moreno y Escandón que no puede considerarse como un mero episodio educativo de la ciudad de Santa Fe. En cierto sentido, diríamos que en esta época se presenció un cambio ideológico en algunos sectores de la elite de colegiales y catedráticos, que se convirtieron en agentes activos del progreso, principalmente para cambiar la mentalidad que se tenía frente a la concepción de las ciencias.

Sin embargo, el sector que se oponía a la reforma del Plan de Estudios no compartía estos progresos. Para ellos la aplicación del nuevo método significaba retroceso y caos para el Virreinato. El rector del Colegio del Rosario, quien ya desde 1775 había presentado una propuesta paralela a la del fiscal Moreno, precisa la situación como "triste y de última ruina" 44 .

Este rector señala que la causa principal de esta situación se debe a la aplicación del Plan de Moreno, "por ser sumamente perjudicial" 45 , y principalmente por haberse ordenado que no se jurara doctrina alguna. Para el rector esta nueva norma iba en contra de las Constituciones de Colegio que señalaba que se debía jurar la doctrina de Santo Tomás ${ }^{46}$. De todas maneras se debe tener presente que este rector no estaba solo porque un grupo del claustro colegial le apoyó para solicitar que se volviera al antiguo método ${ }^{47}$.

También era evidente que la situación política-educativa había cambiado en el Virreinato con el apoyo que el visitador Gutiérrez de Piñeres le otorgaba a la comunidad de Santo Domingo y en efecto el Plan de Moreno se suspendió por la Junta de Estudios del 16 de octubre de 1779. Esta Junta ordenó que se enseñara y

reservó el derecho de ser el titular de la misma. Archivo General de Indias en adelante AGI. Sección Quinta, Audiencia de Santa Fe, leg. 759. Véase Soto ArAngo, D. (1989). Op. cit., pp. 38 a 41.

${ }^{43}$ ACMR. Volumen 125, Libro $1^{\circ}$ de Colegiales, fls. 9-10

${ }^{44}$ ACMR. Vol. 125, libro $1^{\circ}$, Colegiales, fl. 5v .

${ }^{45}$ Doc.cit., fl. $5 \mathrm{v}$.

${ }^{46}$ Doc.Cit., fl. $5 \mathrm{v}$.

47 Carta de los alumnos del Colegio San Bartolomé, julio de 1778. AGI, Sección Quinta, Audiencia de Santa Fe, leg. 759. 
explicara "la filosofía del método escolástico"48. Como era de esperar Eloy Valenzuela se retira de la vicerrectorado del Colegio de Rosario y entra a trabajar con el arzobispo Caballero y Góngora ${ }^{49}$ quien le ordena de sacerdote y trabaja con éste en el cargo de secretario.

Conviene destacar que la influencia de José Celestino Mutis sobre Eloy Valenzuela fue permanente. De hecho, cuando se aprueba la Expedición Botánica, en 1783, Mutis lo vincula como subdirector de ésta y le traslada a Mariquita. Es allí donde escribe el Primer diario de la Expedición Botánica del Nuevo Reino de Granada $^{50}$. En esta obra describe el viaje que realizó desde Santa Fe hasta la citada población de Mariquita en donde permaneció durante un año en sus investigaciones botánicas.

Es importante apuntar que Valenzuela siguió los pasos de su protector Mutis en lo académico y religioso. Asimismo, retomando su tarea de sacerdote se retira al curato de Bucaramanga donde desarrolla una labor loable en el desarrollo de la región y en el estudio y descripción de plantas de la zona.

En esta población desarrolló tareas propias de un administrador Ilustrado de la Corona, entre otras, "la erección de un nuevo templo, la construcción de caminos, el incremento de la agricultura, mejorando la calidad de los pastos y de las especies

${ }^{48}$ ICFES.(1981): «Plan propuesto por la Junta de Estudios de 1779», en Compilación de normas de educación superior, La Colonia. pp. 120 s.s.

49 Antonio Caballero y Góngora nació en Córdoba el 24 de mayo de 1723 y muere en el 24 de marzo de 1796 en la misma ciudad. Viajó a América como obispo de Mérida (Yucatán) en 1775. En este cargo estuvo hasta 1778 porque fue nombrado arzobispo de Santa Fe el 2 de septiembre de 1777. Se posesionó del cargó de arzobispo el 24 de marzo de 1779. Gobernó el virreinato de la Nueva Granada de 1782 a 1789. Durante su gobierno fundó la Expedición Botánica en 1783, restableció la cátedra de matemáticas en 1786 y presentó el Plan de estudios en 1787.Vivió en Cartagena (Turbaco) de 1784 a 1789. Antes de regresar a España en 1789, para ocupar el cargo de arzobispo de Córdoba, donó su biblioteca al arzobispado de Santa Fe. Entre los libros que obsequió se encontraban los de Newton, Locke, Buffon, Fleury, Montaigne, Montesquieu y Blaise Pascal. PÉrez AyAlA, J. M. (1951). Antonio Caballero y Góngora, virrey arzobispo de Santa Fe, 1723-1796. Bogotá: Imprenta Municipal, p.200.

50 Pérez Arbelaez, E. y Acevedo Díaz, M. (1952). Apuntamientos. Primer diario de la Expedición Botánica del Nuevo Reino de Granada por V.E. Agregado científico de ella, el cual comprende desde el día 29 de abril de 1783 hasta el día 8 de mayo de 1784. Bucaramanga: Biblioteca Santander, vol. XXI, 1952. 427 pp., y en Instituto Colombiano de Cultura Hispánica (1983). Bogotá, $458 \mathrm{pp}$. 
de caña dulce". ${ }^{51}$ Podríamos añadir que su convicción de una nueva política para el desarrollo del reino le llevó a costear el camino de Bucaramanga a la aldea de Chita para traer la sal.$^{52}$

Como puede verse, a través de sus escritos, no sólo investigó las plantas sino que también propuso los medios para mejorar la producción y la calidad. Entre sus obras conocidas podemos citar:

- "Informe del cura de Bucaramanga sobre reducir los caseríos del campo a poblaciones urbanas". Bucaramanga, 30 de agosto de $1802^{53}$.

- "Flora de Bucaramanga". Bucaramanga, 1808.

- "Noticia de una especie de Grama útil para potreros o prados artificiales", ${ }^{4}$ 1809.

- "Noticia sobre la caña solera", ${ }^{55} 1809$.

- "Noticia de una mina de alumbre y otros fósiles", ${ }^{56} 1810$.

- "Plana estadística del curato de Bucaramanga", ${ }^{57}$ 1828-1832-1833.

Nos interesa reseñar aquí la extensa correspondencia botánica que sostuvo Valenzuela con José Celestino Mutis. Esta relación epistolar es amplia ${ }^{58}$ y de ella hace gala el sabio gaditano al señalar que "descansa mi corazón cuando hablo con Ud., cada carta de Ud. es para mi tan apreciable como lo eran las mías para Linneo,

51 Acevedo DíAz, M. (1944). «Genio y figura del doctor Eloy Valenzuela», en Estudio, Órgano del Centro de Historia de Santander, Vol. 13, nº155. Bucaramanga, octubre de 1944, p. 235.

52 Acevedo DíAz, M. (1944). Op. cit. p. 227-259.

${ }^{53}$ El original de este documento, señala Enrique Pérez Arbelaez, que lo conserva Otero D`Costa. Otero D`E Costa, E. (1934). «Escritos del padre Valenzuela», en Estudio, Órgano del Centro de Historia de Santander, Bucaramanga, año III, nº s. 30-31, 1934.

${ }^{54}$ Publicado en Semanario del Nuevo Reino de Granada, Santa Fe de Bogotá, enero 8 de 1809.

${ }^{55}$ Publicado en Semanario del Nuevo Reino de Granada, Santa Fe de Bogotá, enero 8 de 1809.

${ }^{56}$ Cartagena de Indias, Diego Espinosa de los Monteros, 1810, p.14.

${ }^{57}$ Santa Fe, Bruno Espinosa de los Monteros 1829-1832 y 1834.

${ }^{58}$ La última carta de la que tenemos conocimiento que le escribió Valenzuela a Mutis es la de julio 19 de 1808, teniendo en cuenta que Mutis muere el 11 de septiembre de 1808. En la citada carta le manifiesta que le remite a Mutis "las dos mejores piezas que guardaba" de las gramíneas como una muestra de gratitud. Hernández De AlbA, G.(1975). Archivo Epistolar del sabio naturalista don José Celestino Mutis. Cartas al sabio Mutis. Letras H-Z. Bogotá: Editorial Kelly, Tomo IV, pp.2622263. 
quien, si hoy viviera celebraría no menos la sabia correspondencia con Ud". 59 Mutis le dedica a Valenzuela la planta con el título de "el Genus Valenzuelia" que correspondía a un género nuevo dentro de la flora bogotana.

Por su parte, Francisco Antonio Zea (1762-1822) le solicitó al botánico español José Antonio José Cavanilles (1745-1804) que le dedicase una planta "al sobresaliente don Eloy Valenzuela digno de tener lugar en la historia de la botánica". ${ }^{60}$ En la descripción que da Zea de Valenzuela señala que se ha "retirado a Bucaramanga donde se ha dado al estudio de la medicina sin abandonar la botánica. Como cura del lugar tiene mil proposiciones de adelantar sus descubrimientos en todos los ramos de la Historia Natural. Sé que escribía la historia de los Juncos dibujando él mismo las láminas de tan hermosas plantas. Sin salir de estos reinos tiene allí abundante materia para muchos escritos. En la flora de Bogotá hay muchos descubrimientos suyos y el Dr. Mutis le ha dedicado un precioso genero" ${ }^{\text {, }}$.

Una vez más, es posible que Mutis influyera en la carrera académica de Valenzuela al ser designado por don Pedro Martínez de Pinillos (1748-1809) ${ }^{62}$ para que elaborara las Constituciones y el Plan de Estudios de Filosofía para el Colegio de San Pedro Apóstol de Mompox en 1806. Obvio es decir que Valenzuela adelantó en estos documentos su pensamiento sobre la enseñanza de la botánica y la manera como él desarrollaría una Expedición Botánica en esta región del norte del virreinato de la Nueva Granada.

59 ACEVEDo DíAz, M. (1944):«Genio y figura del doctor Eloy Valenzuela», en Estudio, Órgano del Centro de Historia de Santander, vol. 13, $\mathrm{n}^{\mathrm{o}}$ 155. Bucaramanga, octubre de 1944, p. 232. Hernández De AlbA, G. (1975). Letras H-Z, Tomo IV, pp. 256-258. Hernández De AlbA. G. (1968). Cartas de José Celestino Mutis. Bogotá, Editorial Kelly, tomos I y II.

${ }^{60}$ Carta de Zea a Cavanilles, Cádiz, 23 de enero de 1799. Archivo Cavanilles en adelante $A C$, en el Real Jardín Botánico de Madrid en adelante ARJB, carta $n^{\circ} 10$, numeración nuestra.

${ }^{61}$ Carta de Zea a Cavanilles, Cádiz, 4 de febrero de 1799. $A C$, en el $A R J B$, carta $n^{\circ} 11$, numeración nuestra.

62 Nació en la villa de Torrecillas de los Carneros en la provincia de Burgos el 18 de enero de 1748 y murió en Cartagena el 22 de mayo de 1809. Llegó a Cartagena en 1767 y se instaló en Mompox en 1775 donde se casó con Tomasa de Nájera (1750-1825). De profesión comerciante, ocupó cargos relevantes en la villa de Mompox como el de comisario, alcalde, regidor y procurador general. En 1796 fue nombrado diputado del Consulado de Cartagena en Mompox pero no aceptó. Hernández De Alba, G. (1926). «El Colegio San Pedro Apóstol en Mompox y su fundador don Pedro Pinillos», en Estudios Históricos. Bogotá, Talleres de Ediciones Colombia, 1926, pp.106-131. LA Voz DE Mompox. (1932): «Colegio Universidad de San Pedro Apóstol. Semblanza del fundador don Pedro de Pinillos», Mompox, mayo 21 de 1932, nº 17. 
Es significativo que en 1808, Eloy Valenzuela, desde su curato de Bucaramanga, solicita al juzgado eclesiástico la dispensa de su residencia para ir a ejercer de rector del Colegio de Mompox para el que ha sido nombrado. Sin embargo, el viaje no lo realizó y nunca llegó a ejercer la rectoría del ColegioUniversidad de Mompox donde hubiese adelantado el vasto proyecto de la Expedición Botánica para la región de Mompox.

Consideramos que los hechos políticos de 1810 le impidieron trasladarse a la ciudad de Mompox debido a que esta villa tomó partido por la independencia y Valenzuela en esta época continuaba siendo monárquico ${ }^{63}$.

\section{LAS CONSTITUCIONES DEL COLEGIO-UNIVERSIDAD DE SAN PEDRO APÓSTOL: UN MODELO DEL PENSAMIENTO ILUSTRADO}

Las Constituciones que vamos a analizar fueron presentadas por Eloy Valenzuela y las firma D. Pedro Martínez de Pinillos el 13 de abril de 1806. Las Constituciones presentan 12 Títulos y comprenden: "1. Sobre edificios sus aposentos y oficinas; 2. Empleados; 3. Del recibimiento de los colegiales; 4. Del traje y vestido de los colegiales; 5 . De la pitanza o alimento diario; 6 . Estudio y su distribución; 7. Exámenes; 8. Ejercicios de devoción; 9. Delitos y penas; 10. De los sirvientes; 11. De Constituciones Generales; 12. Prevenciones y constitución de por entonces" ${ }^{\prime 64}$.

Hay que decir, que el fundador del Colegio D. Pedro Martínez Pinillos le otorgó a Valenzuela plenos poderes para que le representará en Santa Fe en todo lo relativo a la aprobación de las constituciones de su Colegio de la villa de Mompox $^{65}$. Las gestiones son eficientes porque de inmediato el fundador, su

${ }^{63}$ A Valenzuela se le había concedido un permiso de diez y ocho meses para arreglar sus asuntos en Bucaramanga y realizar su traslado a Mompox.

64 "Constituciones para el Colegio de San Pedro Apóstol de Mompox. Las firma Pedro Martínez de Pinillos, fundador del Colegio, pero fueron elaboradas por el presbítero Eloy Valenzuela", Mompox, 13 de abril de 1806. Archivo General de la Nación de Colombia (AGN), Sección Colonia, Fondo Conventos, tomo 22, fls. 483-515. Publicadas en HernÁndez De AlBA, G.(1986). Documentos para la historia de la educación en Colombia. Bogotá: Editorial Kelly, tomo VII, pp. 25 a 71. Se citará este documento.

65 «Poder de don Pedro Martínez Pinillos a favor de Eloy Valenzuela para que lo represente en Santa Fe en las diligencias pertinentes a la erección del Colegio de San Pedro Apóstol de Mompox y elabore los documentos necesarios», Mompox, 9 de julio de 1806. Archivo General de la Nación de Colombia (AGN), Sección Colonia, Fondo, Colegios, tomo VI, fls. 504-505. 
esposa y el Procurador le solicitan al virrey que se nombre a Valenzuela rector y catedrático de filosofía del nuevo Colegio-Universidad de Mompox. ${ }^{66}$ El fiscal dio la aprobación y el virrey le nombró en el cargo solicitado. ${ }^{67}$ Como era de esperar de inmediato Valenzuela se lo comunica a su maestro Mutis ${ }^{68}$ e inicia las gestiones del permiso para hacerse cargo de la rectoría del citado colegio que, como hemos comentado, no llegó a ejercer. ${ }^{69}$

De las citadas Constituciones analizaremos sólo aquellos artículos que tiene que ver con los aspectos más avanzados en relación directa con el pensamiento Ilustrado.

En primera instancia las Constituciones señalan un elemento novedoso en los estudios superiores del virreinato como es la introducción del Claustro en la organización de la Institución. Este claustro de colegiales elegía a: Vice-rector, Consiliarios, Procurador, Bibliotecario y Censor. El rector era nombrado por el Patrono, es decir, por el virrey ${ }^{70}$.

Un segundo aspecto, se refiere al hecho que se acaben con las informaciones` que determinaban, hasta ese momento, en los colegios coloniales que sólo se permitía el ingreso a los de raza blanca. Se dice: "ha de estar patente a todo el

66 «Don. Pedro Martínez Pinillos y su esposa proponen como rector del nuevo Colegio a D. Eloy Valenzuela», Mompox, 13 de agosto de 1806. Archivo General de la Nación de Colombia (AGN), Sección Colonia, Fondo, Colegios, tomo VI, fls. 518 v. "Cándido Nicolás Girón, Procurador de los del número y don Pedro Martínez Pinillos solicitan que Eloy Valenzuela sea el rector del nuevo Colegio y el primer catedrático de Filosofía porque el mismo ha elaborado las reglas del Colegio", Santa Fe, 16 de agosto de 1806. Hernández De Alba. G. (1986). Documentos para la Historia de la Educación en Colombia, tomo VII, 1804-1809. Bogotá: Editorial Kelly, pp. 75-76.

${ }^{67}$ El 17 de agosto de 1806 el Fiscal opina que no existe inconveniente para nombrar a Eloy Valenzuela rector y primer catedrático de Filosofía del Colegio de San Pedro Apóstol de Mompox. El 12 de diciembre del mismo año se nombra a Eloy Valenzuela primer catedrático de Filosofía y el 9 de mayo de 1807 se le nombra rector. Hernández De AlBA, G.(1986). Documentos para la Historia de la Educación en Colombia, tomo VII, 1804-1809, Bogotá: Editorial Kelly, pp. 77-78.

68 «Carta de Valenzuela a Mutis, donde le comenta que tiene el título de rector y catedrático para el Colegio de Mompox», Bucaramanga, 6 de septiembre de 1806. ARJB, Sección Mutis, Serie AA, ${ }^{\circ}$ 455.

69 «Don. Eloy Valenzuela, cura de Bucaramanga, solicita al juzgado eclesiástico la dispensa de su residencia para ir a ejercer de rector del Colegio de Mompox, para el que ha sido nombrado». Bucaramanga, 1808. Biblioteca Nacional de Colombia, en adelante BNC, Sección Libros Raros y Curiosos, Manuscritos. Pieza 22, fls. 505-531.

${ }^{70}$ Hernández De Alba, G. (1986). Op. cit., p. 31. 
mundo. Se han de admitir ricos y pobres, blancos, mulatos, menestrales y aprendices, de todos los oficios y hasta los muchachos descalzos, con tal que no estén sucios ni contagiados. El maestro cuidará de separarlos, en bancos o mesas distintas" $"$.

El aspecto que hemos señalado del cambio que realizó a las informaciones tradicionales se refiere al hecho de no pedir la hidalguía ni limpieza de sangre. Se especificaba que "si sus padres o abuelos han sido negros de raza, o esclavos de condición, con cuyo favorable despacho bastará para que sean admitidos al colegio y tratados como los otros" ${ }^{, 72}$. Con esta perspectiva se agrega en la nota correspondiente a las informaciones que: "si solamente se admiten nobles, se quedarán muchos sin este beneficio. $\mathrm{Y}$ se perderán grandes talentos $\mathrm{y}$

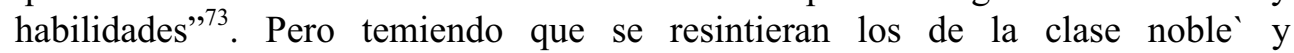
desampararan el colegio, agregaba que "el remedio es, que a todos esté patente esta carrera del ingenio y del estudio y que separados en clase, no se igualen, ni confundan, las condiciones" ${ }^{\text {"74 }}$.

Para entender el Plan Ilustrado en su avance frente al ingreso de los mulatos es decisivo analizar el porcentaje de la población y la política que se fue desarrollando frente a la libertad de los esclavos en la modalidad de comprar la misma por parte de ellos o por que su amo la otorgaba por los buenos servicios. Además, se debe tener en cuenta que estaba en vigencia la Real Cédula de Gracia al Sacar, expedida el 3 de junio de 1793 y ratificada el 10 de febrero de 1795. La citada Cédula concedía igualdad civil a la aspiración de los pardos, mediante el pago de una cantidad de dinero a los derechos reservados hasta entonces a los blancos y notables ${ }^{75}$.

Un tercer aspecto, se refiere al espíritu nacionalista. Indica que el vestido debería ser con algodón nacional y se debería usar el sombrero de caña "ya que se ve que es en obsequio de la industria popular de esta villa" ${ }^{, 76}$. Es significativo que

71 «Constituciones para el Colegio de San Pedro Apóstol de Mompox», 13 de abril de 1806. Hernández De AlBA, G. (1986). Op. cit., p. 36.

${ }^{72}$ Ibid., p. 36

${ }^{73}$ Ibid, p. 36

${ }^{74}$ Ibid., p. 36

75 Brito FigueroA, F. (1987). Historia económica y social de Venezuela. Caracas: Universidad Central de Venezuela, p. 1228.

${ }^{76}$ Hernández De Alba, G. (1986). Op. cit., p. 36. 
en el alimento propone los típicos de la villa como: el pastel de hoja o el buñuelo de sal porque es "uso de la villa y es arreglado, a más que fomenta las industrias de

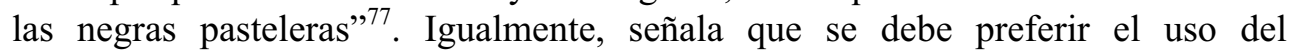
"chocolate por ser mejor bebida y es de nuestra propia cosecha. Su mayor consumo redunda en beneficio de nuestra agricultura, por eso no más le desprecian los extranjero" ${ }^{\prime 78}$. En cambio rechaza el uso del café y del té por ser extranjeras.

El cuarto rasgo característico que le imprime Valenzuela a las Constituciones fue el de la defensa del estudio de las Ciencias para el reconocimiento científico y de explotación de las riquezas naturales del territorio americano. Es importante destacar que señala tres Facultades: la de Filosofía, Derecho, Medicina y otra de Química $^{79}$. Dentro de los nuevos estudios se encontraba la qímica, física, anatomía, la botánica, la música, el dibujo, contaduría y hasta el juego de la pelota y el de la raqueta.

Es curioso pero suprime la Facultad de Cánones. A cambio, es necesario valorar en su justa medida la propuesta que realiza de una expedición botánica realizada por los alumnos del nuevo colegio-universidad. Este Plan comprende varios aspectos. En primer lugar una descripción de la población de la región. Esta comprendía: "número de familias y personas, según sus diferentes clases, edades y razas. Continuarán los números de casados, nacidos y muertos, con distinción de castas, sexos y edades. Se expresarán las calles, plaza, cuarteles y casa de la villa, las tiendas de forasteros o transeúntes, las del almacén, pulperías y talleres. Acompañará una factura de los principales géneros comerciales con sus precios corrientes y otro casi igual de los comestibles comunes" ${ }^{80}$. Al respecto, indica que se debe incluir la información sobre: "consumos anuales, de los cargamentos, y buques y de los productos líquidos de aduana, aguardiente y tabaco". ${ }^{81}$

Incluye dentro de este Plan un análisis del clima de la región donde se indicará "más o menos calor, las variaciones de la atmósfera y corriente de los vientos" $"$.

${ }^{77}$ Ibid., p. 46.
78 Ibid., p. 46.
${ }^{79}$ Ibid., p. 64.
${ }^{80}$ Ibid., p. 67.
${ }^{81}$ Ibid., p. 67.
${ }^{82}$ Ibid., p. 67. 
La formación académica para realizar esta expedición se encuentra desde "los huertos escolares". Lo describe como: "un huerto con dos patios o cuadros, uno para yerbas y otro para arbustos" ${ }^{\prime 3}$. Para esto era indispensable la enseñanza de la botánica y materia médica vegetal. La expedición como parte de las Constituciones, las localiza en el último capítulo. Indica que comprenderá la "flora de esta villa o la colección de todas las plantas, espontáneas de su suelo y comarca dibujadas y coloridas al natural con hojas, flores y frutos y la anatomía sexual característica" ${ }^{\sharp 4}$. Como es lógico, por la influencia de Mutis, la clasificación se realizaría por Linné. Las plantas las clasifica por: alimento, medicina e industria.

Hay que decir, que la expedición propuesta también tenía cobertura sobre los animales. Éstos los clasifica en: cuadrúpedos, aves y peces ${ }^{85}$. Éstos se describirían según el uso y lenguaje adoptado por los naturalistas. Se refiere a: "la descripción característica y completa del género, especie y variedad; la calidad de silvestre, doméstico, comestible, cantador, estable o transmigrante, etc." ${ }^{" 86}$. La última clasificación se refiere a: los reptiles, insectos y gusanos. A estos les reserva un tomo para láminas y descripciones.

Por último la formación sobre la astronomía se daría en un cuarto para "las máquinas de física, para la demostración de sus lecciones y de los más preciosos instrumentos de la astronomía" ${ }^{\prime 87}$.

Pero, otro elemento novedoso en este apartado es el de los viajes que deberían realizar los estudiantes. Para él "el espíritu de los viajes.... Es el medio por donde se adquieren fácilmente los conocimientos políticos, económicos y literarios, con que se crían las ciencias, las artes y los grandes establecimientos" ${ }^{\prime 8}$. El viaje se realizaría a Europa ojalá por la mayoría de los estudiantes. El colegio financiaría

\footnotetext{
${ }^{83}$ Ibid., p. 65.

${ }^{84}$ Ibid., p. 67

${ }^{85}$ Ibid., p. 68.

${ }^{86}$ Ibid., p. 68.
}

${ }^{87}$ Soto Arango, D. y ArboledA, L. C. (1995). «Los estudios de Botánica en los planes ilustrados del virreinato de la Nueva Granada», en Revista ASCLEPIO de Historia de la Ciencia del Consejo Superior de Investigaciones Científicas, Madrid, Vol. XLVII, nº 2, 1995, pp. 113- 137. SoTO ARANGO, D. (2002). «La política del 'Despotismo Ilustrado' en la educación superior en el virreinato de la Nueva Granada», en Revista SYNTHESIS. Cadernos do Centro de Ciencias Sociais. Universidade do Estado do Rio de Janeiro, 2002, pp. 19 a 28.Hernández De AlbA, G. (1986). Op.Cit., p. 29.

${ }^{88}$ Ibid, p. 70 
dos alumnos de filosofía y de medicina que no pasarán de veinticinco años. El viaje duraría de 18 a 20 meses. Los estudiantes seleccionados a su regreso deberían dictar dos cursos de filosofía y de medicina. Deberían establecer contactos con científicos de España, París y Londres. Además deberían traer a su regreso: "libros, instrumentos, máquinas, aparatos y vasos a lo menos de los más preciosos, para la física, la astronomía, química y anatomía" ${ }^{\text {89. }}$.

Es significativo, que un común denominador de los planes de estudio Ilustrados fue el de la crítica al método tradicional. Quizá el más radical y más avanzado, de todos los que conocemos en esta época en el virreinato de la Nueva Granada, sea el de Eloy Valenzuela. En el Plan señala que la enseñanza escolástica "ha ofuscado y enmarañado los entendimientos. Ha mantenido sus literatos en una inacción y adormecimiento para que nada hagan, nada emprendan y ni aun así siquiera aconsejen en beneficio de su país." ${ }^{.90}$. En las Constituciones se reafirmaba en su posición al plantear que la filosofía de Goudin "atolondra, enmaraña y confunde y así no conviene mucho esmero en estudiarla." ${ }^{\text {91 }} \mathrm{Y}$ del método que tradicionalmente se utilizaba, decía que "no ilustraba ni cultivaba las mentes" indicaba se debía seguir el método experimental.

El quinto aspecto, se refiere a la identidad con la política del Despotismo Ilustrado ${ }^{93}$ y el movimiento cultural global de la Ilustración dentro del eclecticismo de adaptación a la realidad de la zona de Mompox. Para Valenzuela, los colegiales deberían dar muestras de "amor al soberano y sumisión a su gobierno" 94 . Por lo tanto deberían estar dispuestos para ir a la guerra. Al respecto señala: "cuando acontezca que en algún punto de la costa inmediata se presente fuerza armada o expedición enemiga, inmediatamente el colegio pondrá a disposición del

${ }^{89}$ Ibid, p. 71.

90 «Constituciones para el Colegio de San Pedro Apóstol de Mompox, 13 de abril de 1806». HernÁndez De AlbA, G. (1986). Op. cit., p.50

${ }^{91}$ Ibidem, p. 50

92 «Constituciones para el Colegio de San Pedro Apóstol de Mompox, 13 de abril de 1806». Ibidem, p.50.

93 "Despotismo porque se mantuvo al pueblo apartado de la cosa pública, ilustrado porque hubo un intento consciente de aplicar los logros científicos y técnicos de la época". FedELMAN, M. (1972). «El Siglo XVIII», en Cuadernos de Estudio 22, Buenos Aires, p. 73. HerR, R.(1964). España y la revolución del Siglo XVIII. Madrid: Aguilar, p.7.

94 «Constituciones para el Colegio de San Pedro Apóstol de Mompox, 13 de abril de 1806». Ibidem, p.60. 
excelentísimo señor virrey del reino la lista de los colegiales que se hallen aptos para las armas" $" 95$. Pero además, como política del Colegio se indica que estaría dispuesto a dar dinero de los ahorros y economía de la Institución.

Un sexto aspecto se refiere a oponerse al sectarismo religioso. En este caso, rechaza cualquier manifestación religiosa que distraiga a los alumnos de las tareas de aprendizaje. Hemos anotado que en estas Constituciones conviene destacar que prima el sentimiento civil al religioso. Se disminuye las horas de rezo al ponerse media por la mañana y la otra media por la tarde. Pero lo más importante para Valenzuela de las devociones prescritas es "la aplicación al trabajo" 96.

En este punto la más importante novedad es la introducción en la enseñanza de los catecismos civiles el que se debería dar "junto o después de aquel"97. Por lo visto si el hombre necesitaba saber lo necesario para salvarse también era substancial el estudio del comportamiento en la sociedad. Por consiguiente, lo valores sociales, entre otros, el de la honradez frente a la estafa eran prioritarios en un buen ciudadano ${ }^{98}$.

En este aspecto, es significativo que el Plan de estudios de Filosofía le da gran importancia a la formación de "las relaciones y deberes como ciudadano y miembro de la sociedad"99. Insiste en la formación del ciudadano y en las "obligaciones del vasallo para con el soberano, del súbdito para el magistrado; las de un amigo con otro; las del comerciante y el mercader; del campesino, del militar; del mayordomo etc., y últimamente las del sacerdocio" ${ }^{\prime 100}$. No deja de ser curioso que Valenzuela insista en que los estudiantes que decidan el sacerdocio deben pensarlo sin precipitarse.

\footnotetext{
95 Ibid, p. 61.

${ }^{96}$ Ibid, p. 53.

${ }^{97}$ Ibid, 54.
}

${ }^{98}$ Decía: "así también debía saber y aún predicársele lo que no debe omitir, para mantenerse sin petardear o estafar". Ibid, p. 54.

99 «Plan de estudios de Filosofía, para el Colegio de San Pedro Apóstol de Mompox, elaboradas por Eloy Valenzuela», 2 de septiembre de 1806. Archivo General de la Nación de Colombia (AGN), Sección Colonia, Fondo Conventos, tomo 22. BNC, Sección Libros Raros y Curiosos, Protocolo de Instrucción Pública, 1672-1818. Número 338, fls. 298-309. Publicado en: Soto ARANGO, D. (1994). La Ilustración en las Universidades y Colegios Mayores de Santa Fe, Quito y Caracas. Bibliografia crítica y fuentes. Bogotá: COLCIENCIAS- Universidad Pedagógica Nacional, p.231.

${ }^{100}$ Ibid, p. 231. 
El séptimo punto relevante, que apuntamos, se refiere al calendario académico y a los horarios. Las Constituciones reducen de tres a uno el número de meses de vacaciones por considerar que "es mucha pérdida de tiempo y demasiado descanso aun para los trabajadores de hacha y machete; es convidarles con la flojera cuando se les había de enseñar la aplicación laboriosidad y constancia." ${ }^{101}$.

En el capítulo del estudio y distribución de horario además de lo señalado, específica la jornada de estudio y la cátedra de filosofía, la de música, la de dibujo y hasta el juego de la pelota y el de la raqueta. Considera prioritario el primer año de estudio enseñarle al estudiante la elaboración de cartas personales, mercantiles, letras de cambio y "todo uso de comerciantes"102, con el objeto de que si abandonaba los estudios al finalizar ese año, por lo menos este ciudadano podría trabajar de oficial de una contaduría.

El octavo aspecto que cambia la estricta evaluación del aprendizaje por la interacción con los alumnos la relaciona Eloy Valenzuela en el capítulo séptimo de las Constituciones. Indica con detalle en los exámenes parciales y el rigor del aprendizaje, que debe ser comprobado día a día. Los exámenes los clasifica en públicos y privados. Los públicos son los anuales "para estímulo y lucimiento de los alumnos y son los que en el reino se llaman conclusiones" ${ }^{\text {103 }}$. Los exámenes privados se presentan al final de la jornada tomando la modalidad de una tertulia entre profesor y estudiante. Valenzuela en el Plan de Filosofía reseña con mayor detalle los exámenes en el apartado de los "calendarios hortenses". Al respecto dice: "Día por día y hora por hora, aquéllos en cabeza de renglones atravesados y éstas al frente de los verticales, se anotará lo que sea digno de observación y cada día de paso se presentarán para su examen que seguramente se convertirá en una tertulia muy curiosa en que un maestro instruido y celoso podrá infundirles muchas noticias de la fisiología vegetal y lo que es más es la afición al culto metódico y raciocinado" ${ }^{\prime 104}$.

La novena aportación, no sólo en cuanto a la peculiaridad, sino también en lo que significaba en el juego de poderes políticos del Virreinato es el referente a la provisión de las cátedras. En efecto, la condición de eliminar el espíritu de partido

101 «Constituciones para el Colegio de San Pedro Apóstol de Mompox, 13 de abril de 1806». En Hernández De Alba, (1986). Op.Cit., p. 43.

102 Ibid, p. 46

103 Ibid, 47.

${ }^{104}$ Soto Arango, D. (1994): Doc. Cit., p. 231. 
o el de no favorecer a los egresados del Colegio-Universidad de Mompox van a diferenciar estas Constituciones de las de los colegios y universidades de Santa Fe. De ahí que, para la posesión, no se exige juramento alguno "mucho menos de seguir determinada escuela o partido" 105 . Indica que lo contrario es un abuso que "ha perjudicado mucho a las ciencias en España y en otras comunidades que se dividen en Tomistas, Escotistas, Javieristas, etc. Jamás los de un partido han podido convertir a los de otro y esto prueba, o que van distantes de la verdad o de la buena fe; lo cierto es que nada interesan al beneficio común y que sus contiendas ni siquiera divierten como las del Quijote"106.

Asimismo, por las razones ya argumentadas el concurso de catedráticos se determina que sea público y la convocatoria se haría en todo el país. La terna saldría de la votación que realicen los miembros de la Junta y colegiales y la elección final la realiza el real patronato. Por otra parte, una vez aprobado el real Colegio-universidad, el virrey procedió a nombrar los profesores previa oposición que hicieron a los cargos.

El décimo punto que consideramos significativo es el hecho que proponga refundar la Sociedad Económica de Amigos del País que se había organizado en 1784 en esa ciudad y que ya no existía. Sustentaba la creación de esta institución Ilustrada porque el colegio "no solamente debe ser un cuerpo literario sino también patriótico"107.

El doceavo aspecto que representa la orientación Ilustrada de las citadas Constituciones se centra en los autores y textos de carácter Ilustrado que se señalan como obligatorios en la enseñanza del nuevo Colegio-Universidad. Se crítica a Antonio Goudin (1639-1695) ${ }^{108}$ que se mandó estudiar en Santafé a partir del Plan

105 Constituciones. Doc. Cit., p.49.

106 Constituciones. Doc. Cit., p.49.

${ }^{107}$ Ibid, p. 70

${ }^{108}$ Padre dominico "pertenece a los escolásticos tradicionales de la decadencia de aquellos que, frente a la filosofía moderna, siguen considerando a la física como parte integrante de la filosofía , pasan por alto o impugnan las nuevas teorías científicas y filosoficas y reproducen en sus tratado las doctrinas escolásticas aunque más sistematizadas y ya no en forma de comentarios de Aristóteles". Su principal obra: Philosophia Tomística Juxta Inconcussa Tutissimaque Divi Thomas Dogmata, quator Tomis comprenhensa, se explicaba en tres años. En el primero toda la lógica; en el segundo, la física general y los tratados del cielo y del mundo y de la generación y de corrupción; en el tercero el tratado del alma y la metafísica”, en SALAZAR, A. (1946). «Los estudios eclesiásticos superiores en el Nuevo Reino de Granada 1563-1810». Madrid: Consejo Superior de Investigaciones Científicas de 
de Estudios de 1779 y representaba el escolasticismo más tradicional y éste había sido adoptado por la orden dominicana a partir de 1756 cuando fue nombrado de Padre General Tomás Boxadors ${ }^{109}$. A cambio s e propone en las Constituciones del nuevo Colegio, como hemos señalado, el estudio de las ciencias naturales fundamentadas en el método matemático de Cristian Wolf (1679-1754). Se considera que este filósofo pertenece a la segunda generación de la Ilustración alemana. Se dice con razón que la filosofía racionalista de Wolff, basada en el método matemático, osciló permanentemente entre las ideas de Descartes y las de Leibnitz, "precisamente por querer aplicar ese método a la filosofía, un campo del pensamiento en donde las especulaciones no son puramente racionales sino también experimentales" $" 110$.

En el virreinato de la Nueva Granada las teorías de Wolff ${ }^{111}$ encajan perfectamente en la mentalidad católica del fiscal Francisco Moreno y Escandón y de Eloy Valenzuela. Se considera que "no disocia el saber de la fe metafísica y religión, concretamente de la religión cristiana""112.

Si bien, Wolf es uno de los autores más citados, no obstante es Isaac Newton $(1732-1808)^{113}$ quien marca la pauta en el cambio de método en estos Planes Ilustrados. En los Planes de reforma de Estudios de Sevilla(1768) y de Alcalá (1771) es obligatorio mientras en el virreinato de la Nueva Granada ya se tenía experiencia en la enseñanza de este autor y el Fiscal Moreno lo recomienda con desconfianza en su método del Plan de 1774. Posiblemente, esta actitud se deba a

España. CSIC., pp.178-179. HirsChBerger, J (1965): Historia de la filosofía, Barcelona: Herder, tomo I, pp. 519-520.

${ }^{109}$ Dominguez, D. (1931). Historia de la filosofia. Colombia: Santander, p 399.

${ }^{110}$ HirschBerger, J. (1965). Historia de la filosofia, Barcelona: Herder, tomo I, p. 165.

111 Véase en Quintero, J. (2003). «La huella de Christian Wolf en la educación neogranadina», en Recepción y difusión de textos Ilustrados. Intercambio cientifico entre Europa y América en la ILustración. Madrid. Colecciòn La Ilustraciòn en Amèrica Colonial. Tomo III. RudeCOLOMBIA, Universidad de Halle, ColCIENCIAS, Dirección de Investigaciones. Universidad Pedagógica y Tecnológica de Colombia. Ediciones Doce Calles, Universidad de León. 2002, pp. 133-150.

112 HirschBerger, J (1965). Historia de la filosofía. Barcelona: Herder, tomo II, p. 467.

113 NEWTON, ISAAC (1642-1727). Matemático y físico británico, considerado uno de los más grandes científicos de la historia, que hizo importantes aportaciones en muchos campos de la ciencia. Newton fue, junto al matemático alemán Gottfried Wilhelm Leibniz, uno de los inventores de la rama de las matemáticas denominada "cálculo". También resolvió cuestiones relativas a la luz y la óptica, formuló las leyes del movimiento y dedujo a partir de ellas la ley de la gravitación universal. Obras: Óptica; Principios matemáticos de la filosofía natural (1687).Tomado de: Enciclopedia Microsoft Encarta 2001. 
la polémica que desde 1773 le realizaron los dominicos a José Celestino Mutis por la enseñanza de Copérnico. Quizá por este motivo Eloy Valenzuela no lo menciona en las Constituciones ni en el Plan de Estudios de Filosofía ${ }^{114}$. Debemos indicar que en las Constituciones y en el Plan de Filosofía Valenzuela se inclina en la botánica por Linneo que era la utilizada por Mutis y en el Real Jardín Botánico de Madrid. También hemos de anotar que en el citado real Jardín Botánico se había aprobado un nuevo Plan de estudios de Botánica en 1784 que tuvo repercusiones en América colonial en el "método y textos que fueron los que se recomendaron en México, Perú y en el virreinato de la Nueva Granada" "115. Igual difusión se le dio a los textos de la "Historia natural de Bufon"116.

Otro aspecto, a tener en cuenta en el modelo institucional que se propuso para el nuevo Colegio-universidad es el de la administración de los dineros. Esta actividad quedó en la compañía mercantil Pinillos y Sobrinos con un capital permanente de 120.000 pesos. Los dineros se dispusieron de la siguiente manera: Para los gastos que demandaba el funcionamiento de este plantel destinó sesenta y siete mil seiscientos pesos, cuyos réditos al 5\% anual, que se comprometía a satisfacer oportunamente y con todas las garantías convenientes la razón social "Pinillos y sobrinos", daban lo necesario para pagar el rector y el regente de estudios 250 pesos; al vicerrector 100 pesos; a los dos maestros de primeras letras 220 pesos; a los catedráticos de latinidad, filosofía y teología, leyes y cánones 300 pesos a cada uno; al de medicina 400 pesos; al de dibujo 450 pesos; para premios que estimulasen la aplicación de los jóvenes 100 pesos; finalmente 480 para seis becas a razón de 80 pesos para cada colegial, asignando 300 pesos para un médico con

114 Soto ARANGO, D. y ARBOLEDA, L. C. (2003). «Introducción de una cultura newtoniana en las universidades del virreinato de la Nueva Granada. Recepciòn y difusión de Newton en la Nueva Granada», en Recepción y difusión de textos Ilustrados. Intercambio cientifico entre Europa y América en la Ilustración. Editores académicos: D. Soto Arango, M. A. Puig-Samper, M. Bender y M. D. GonzÀlez RIPOLl. adrid, Colecciòn La Ilustraciòn en Amèrica Colonial. Tomo III. RudECOLOMBIA, Universidad de Halle, COLCIENCIAS, Dirección de Investigaciones. Universidad Pedagógica y Tecnológica de Colombia. Ediciones Doce Calles, Universidad de León. 2.002, pp. 203-216.

115 Soto ArANGo, Diana y ARboleda, Luis Carlos (1995): "Los estudios de Botánica en los planes ilustrados del virreinato de la Nueva Granada", en colaboración con Luis Carlos Arboleda, Revista ASCLEPIO de Historia de la Ciencia del Consejo Superior de Investigaciones Científicas, Madrid, Vol. XLVII, nº 2, 1995, pp. 132-133.

116 Conde de Bufon, Georges Louis Leclerc (1707-1788). Publicó 36 volúmenes de Historia Natural. Véase Dictionary of Scientific Biography (1970). New York. Charles Sxribner's Sons, vol. II, pp. 576-581. 
obligación de asistir a las enfermerías del hospital-hospicio; 200 pesos para un boticario y otro tanto para un capellán ${ }^{117}$.

La Universidad se instaló con las normas de rigor el 29 de agosto de 1809. Interinamente, hasta que Valenzuela ocupara el cargo de rector y catedrático, se nombró al abogado de la Real Audiencia José María Gutiérrez y Cabiedes ${ }^{118}$, quien a su vez desempeñó el cargo de vicerrector y catedrático de filosofía y por lo tanto le correspondió la lección inaugural del curso académico. Gutiérrez y Cabiedes se había distinguido en su época de estudiante por la exposición que realizó en las conclusiones públicas. ${ }^{119}$ También, es de resaltar su participación en la tertulia del Buen Gusto en la ciudad de Santa Fe. Su nombramiento se reseñó en la época de la independencia, en el Correo del Orinoco, de la siguiente manera: "Gutiérrez fue recibido por la Audiencia en el número de abogados, y el Virrey le confirió luego una comisión muy importante para la villa de Mompox, nada menos que para poner en planta el Colegio Universidad que allí se había erigido por Cédula Real a expensas del filántropo español don Pedro Pinillos, hombre bienhechor de aquel país [...]"(Correo del Orinoco, $\left.\mathrm{n}^{\mathrm{o}} 50\right)^{120}$ De todas maneras es importante apuntar que desde el 29 de julio de 1806 el virrey había despachado el edicto del nombramiento de todos los catedráticos, rector y vicerrector.

117 La VOZ DE Mompox. (1932). «Fundación del Colegio-universidad de San Pedro Apóstol». Mompox, mayo 29 de 1932, $\mathrm{n}^{\circ} 18$. Consideramos que el dinero que se establece para Cánones debe ser la de medicina, porque las Constituciones no mencionan en ninguna parte la Cátedra de Cánones.

${ }^{118}$ Fue abogado de la Real Audiencia, después de su regreso de Mompox se dedicó al "ramo científico de Ingenieros" levantó cartas topográficas y planes de fortificación. Fue fusilado en el patíbulo en 1816. Se comenta en el Correo del Orinoco que "él expiró en el patíbulo por el crimen de opinión, quien siempre fue el de los grandes hombres, y el mismo hubiera sido uno de ellos en el teatro del mundo sin una muerte prematura." Correo del Orinoco, $\mathrm{n}^{\circ}$ 50, Angostura, sábado 29 de enero de 1820 .

${ }^{119}$ Se comenta en el periódico Correo del Orinoco que el "primer ensayo de Gutiérrez fue un acto público de aritmética tan bien sostenido, que no solo pudo resolver y demostrar los mas dificultosos problemas, más aún inventar un método mas simple para la extradición de las raíces, el cual fue apreciado por el profundo Mutis, y que por esta recomendación merece ser mencionado en este lugar". Correo del Orinoco, $\mathrm{n}^{\circ}$ 50, Angostura, sábado 29 de enero de 1820.

${ }^{120}$ Correo del Orinoco, n $^{\circ}$ 50, Angostura, sábado 29 de enero de 1820. 
La Universidad funcionó en el antiguo colegio de los Jesuitas ${ }^{121}$. Sus labores duraron poco tiempo debido a que se clausuró en 1811 y sólo se reabre en 1823 bajo la rectoría del Pbro. Luis José Serrano Díaz. ${ }^{122}$ En el Correo del Orinoco se reseña el cierre cuando se comenta la biografía de Gutiérrez, se dice: "Gutiérrez cumplió exactamente con su encargo; y el establecimiento se hubiera adelantado mucho, si no se hubiese sobrevenido la revolución de la Nueva Granada, que obligó al director a partir a la capital con otro joven maestro de leyes, compañero de su fortuna" (Correo del Orinoco, $\mathrm{n}^{\circ} 50$ ). ${ }^{123}$ Este Colegio sufrió los avatares de las luchas políticas en el país y por este motivo sufrió cuatro cierres más en: 1840 a $1845 ; 1858$ a $1872 ; 1895$ a 1896; 1900 a 1905 . Finalmente, en 1936 por medio de la Ley 179 se le da el carácter de Instituto Nacional ${ }^{124}$.

\section{CONCLUSIÓN}

La aprobación Real del Colegio-Universidad de San Pedro Apóstol, localizado en la villa de Mompox, sólo tiene una explicación por estar situado en una Villa de un comercio floreciente y porque el promotor, Don Pedro Pinillos tenía los apoyos en la Corte y el dinero suficiente para que le dieran esta prerrogativa.

El carácter Ilustrado a las Constituciones se las dio don Eloy Valenzuela, primer subdirector, de la Real expedición Botánica. La aplicación de las mismas, sin oposición local, se debió al hecho que no se encontraba ninguna comunidad religiosa regentando estudios en la villa. Los únicos habían sido los jesuitas que fueron expulsados en 1767. Sin embargo el Plan de Filosofía fue duramente criticado por los rectores de los colegios santafereños. El plan de estudios propuesto por Valenzuela se aplicó parcialmente. Hemos comprobado que la botánica se enseño en el último año de Filosofía. Por otra parte, es relevante señalar

${ }^{121}$ El edificio lo compró Pedro Martínez Pinillos en 1801. En el primer piso funcionó el Hospicio $\mathrm{y}$ en el segundo el Colegio. Actualmente funciona en este mismo edificio las oficinas del Ayuntamiento (Alcaldía). LA VOZ DE MOMPOX. (1932): «Apéndice a la monografía de la Universidad». Mompox. n $^{\circ} 20$ del 11 de junio de 1932.

${ }^{122}$ De 1821 a 1815 el colegio fue sede del cuartel patriota; de 1815 a 1820 , sede del cuartel realista; de 1820 a 1823 sede del cuartel patriota. El general Santander lo reabre en 1823. En 1832 se instauran los estudios de Jurisprudencia. LA VOZ DE MOMPOX. (1932): «Apéndice a la monografía de la Universidad». Mompox. no 20 del 11 de junio de 1932.

123 Correo del Orinoco, $\mathrm{n}^{\mathrm{o}}$ 50, Angostura, sábado 29 de enero de 1820.

${ }^{124}$ Debo agradecer la información que me suministró el señor rector del Colegio de Santa Cruz de Mompox, Sr. Orlando Ramírez, el 23 de julio de 1992, en la ciudad de Mompox. El Sr. Ramírez fue rector del Colegio Pinillos como se conoce actualmente al antiguo colegio de San Pedro Apóstol. 
que el nuevo colegio-universidad no tenía problemas de financiación porque esta situación la había dejado resuelta don Pedro Pinillos.

La nueva institución de carácter civil bajo el patronato del virrey y administración del Cabildo Civil se convirtió en la única universidad, con carácter de Mayor, que logró aprobación real y aplicación de sus estatutos Ilustrados en el periodo colonial en el virreinato de la Nueva Granada. Presentó el sello de sumisión a la monarquía y un estilo religioso alejado de la beatería.

La primera universidad del Caribe colombiano, presentó unas características que fueron avanzadas en su época y que aún hoy en día siguen teniendo vigencia como: el método de enseñanza-aprendizaje; la educación experimental; las visitas académicas al extranjero; el ingreso por méritos académicos a los estudios y a la docencia y el estilo nacionalista en la reglamentación de la vida cotidiana.

En definitiva, con las Constituciones de esta primera universidad del Caribe colombiano se ingresa a la modernidad en la enseñanza de los estudios superiores. Sin embargo, este proceso se trunco en 1810. Hemos llegado al siglo XXI y principios como el de la educación experimental, el tipo de exámenes donde prima el diálogo, la visita académica a otros países siguen en las buenas intenciones de la legislación colombiana sin lograr una aplicación de la misma. Por otra parte, la universidad aún no entra en la era de la investigación y se ha convertido en difusora de teorías algunas alejadas de la realidad circundante como lo señalaba Eloy Valenzuela en los comienzos del siglo XIX.

\section{FUENTES}

Anales Del Estado De Bolívar, (s/f): Estadística de Mompox.

ArChivo General De Indias.AGI. Sección Quinta, Audiencia de Santa Fe, leg. 759.

ARCHIVO COlEgio MAYOR Del Rosario: ACMR: 1. "Informaciones de don Eloy Valenzuela, para su ingreso en el Colegio Mayor del Rosario", Santa Fe, 20 de octubre de 1770. Vol. 119, fls 267 a 270; 2. Volumen 125, Libro $1^{\circ}$ de Colegiales, fl. 7. y Volumen 124, fl. 178.

Archivo General De La Nación. Colombia: AGN. Sección Colonia, Fondo Conventos, tomo 22. 1. "Constituciones para el Colegio de San Pedro Apóstol de Mompox. Las firma Pedro Martínez de Pinillos, fundador del Colegio, pero fueron elaboradas por el presbítero Eloy Valenzuela", Mompox, 13 de abril de 1806, tomo 22, fls. 483-515; 2."Lista de estudiantes matriculados en el Colegio de San Bartolomé". Archivo General de la Nación, Fondo Colegio San Bartolomé. Libro 11. 
IBID. Sección Libros Raros y Curiosos, Protocolo de Instrucción Pública, 16721818. Número 338, fls. 298-309.

IBID. Sección Colecciones. Fondo Ortega Ricaurte. "Padrón de la Provincia de Cartagena. Año de 1780”. Censos 1, Caja 37, Documento 11.

IBID. Sección Colonia, Fondo, Colegios, tomo VI, fls. 518 v.

ARCHIVO REAL JARDÍN BotÁnICO DE MADRID: ARJB, Sección Mutis, Serie AA, $\mathrm{n}^{\circ}$ 455: 1. Archivo Cavanilles. en el Archivo Real Jardín Botánico de Madrid: ARJB, carta $n^{\circ} 10$, numeración nuestra.

Biblioteca Nacional De Colombia, BNC, Sección Libros Raros y Curiosos, Manuscritos. Pieza 22, fls. 505-531.

La ley 163 de 1959 declara la ciudad de Mompox Monumento Nacional. Instrucción Pública, no 13531.

Boletines Historiales de la Academia de Historia de Santa Cruz de Mompox:

ICFES.(1981): "Plan propuesto por la Junta de Estudios de 1779", en Compilación de normas de educación superior, La Colonia. pp. 120 ss.

\section{PERIÓDICOS}

CORREO DEL ORINOCO, $\mathrm{n}^{\circ}$ 50, Angostura, sábado 29 de enero de 1820.

LA Voz DE MompoX. (1932): 1. "Colegio Universidad de San Pedro Apóstol. Semblanza del fundador don Pedro de Pinillos", Mompox, mayo 21 de 1932, $\mathrm{n}^{\circ}$ 17; 2. "Fundación del Colegio-universidad de San Pedro Apóstol". Mompox, mayo 29 de 1932, n 18; 3. "Constituciones de la Universidad". Mompox, no 19 del 4 de junio de 1932; 4. "Apéndice a la monografía de la Universidad". Mompox. no 20 del 11 de junio de 1932.

Semanario Del Nuevo Reino De Granada, Santa Fe de Bogotá, enero 8 de 1809.

\section{BIBLIOGRAFÍA}

ACEVEDO DÍAZ, M.(1944). «Genio y figura del doctor Eloy Valenzuela», en Estudio, Órgano del Centro de Historia de Santander, Vol. 13, n $\mathrm{n}^{\mathrm{o}} 155$. Bucaramanga, octubre de 1944

Brito FigueroA, F. (1987): Historia económica y social de Venezuela, Caracas: Universidad Central de Venezuela. Torno III.

CifUENTES, L. (1998). «En Defensa de la Universidad Estatal Chilena», en Ciencia al Día Internacional, Santiago de Chile, v.1, n. 1, abril 1998.

Conde CALDERón, J. (1999): Espacio, sociedad y conflictos en la Provincia de Cartagena. 1740-1815. Barranquilla: Fondo de Publicaciones de la Universidad del Atlántico,

DoCumentos (1983). Mutis y la Expedición Botánica, Bogotá: Ancora Editores 
Fals Borda, O.(1979). Mompox y Loba. Bogotá: Carlos Valencia.

FERNÁNDEZ DE PIÑEREZ, M. (1967). Unas vidas novelescas y un sacrificio glorioso. Mompox: Tipografía el Esfuerzo.

Fedelman, M. (1972). El Siglo XVIII. Buenos Aires: Cuadernos de Estudio 22.

GARRIDO, M. (1993). Reclamos y representaciones. Bogotá: Banco de la República,

GutiÉRrez DE PIÑEREZ, E. (s/f). La fundación de Mompox. Mompox

HERR, R.(1964). España y la revolución del Siglo XVIII. Madrid: Aguilar.

Hernández De AlBA, G. (1926). «El Colegio San Pedro Apóstol en Mompox y su fundador don Pedro Pinillos», en Estudios Históricos. Bogotá: Talleres de Ediciones Colombia,

HeRnÁndez De AlBA, G. (1975). Archivo Epistolar del sabio naturalista don José Celestino Mutis. Cartas al sabio Mutis. Letras H-Z, Tomo IV. Bogotá: Editorial Nelly.

Hernández De AlBA, G. (1968). Cartas de José Celestino Mutis. Bogotá, Editorial Kelly, Tomos I y II.

Hernández De AlBA, G. (1986). Documentos para la Historia de la Educación en Colombia. Tomo VII, 1804-1809, Bogotá: Editorial Kelly

IHEAL (1994). Latine Institut des Hautes Études de l'Amérique / Université de la Sorbonne Nouvelle - Paris III.

LUKÁCS, G. (1989). Sociología de la Literatura. Barcelona: Ediciones Península.

MARINS, P. (1998). «Habitação e vizinhança: limites da privacidade no surgimento das metrópoles brasileiras»». en SEvCHENKO, N. (Org.). História da vida privada no Brasil. v. 3. São Paulo: Companhia das Letras.

MingueT, Ch. (1985). Alejandro de Humboltd historiador y geógrafo de la América española. México, Universidad Nacional Autónoma de México. Tomo II.

MORIN, E. (2002). Os sete saberes para a educação do futuro.Colecção Horizontes Pedagógicos, n. 87. Lisboa: Instituto Piaget.

MORIN, E. (1990). Introduction à la pensée complexe. Paris, ESF.

OCAMPo López, J. (1984). Historia básica de Colombia, Bogotá: Plaza \& Janes.

Otero D`E CostA, E. (1934): «Escritos del padre Valenzuela», en Estudio, Órgano del Centro de Historia de Santander, Bucaramanga, año III, nºs. 30-31.

PeÑas Galindo, D. (1987): Efémeris de Mompox. Cartagena: Espitía Impresores.

Restrepo, J. M. (1974): Historia de la Revolución en Colombia, Medellín: Editorial Bedout.

RouQuiÉ, A. (1972): «Integristes et militaires: les tentatives du nationalcatholicisme en République Argentine», in: MINI-COLOQUE, 1, Les Organisations Religieuses en tant que Forces Politiques de Substitution (Le cas 
des régimes non-pluralistes contemporains), Paris, 27-28 oct. 1972. Anais. Paris: Centre d'Étude des Relations Internationales, Mimeografado.

PÉRez Ayala, J. M. (1951). Antonio Caballero y Góngora, virrey arzobispo de Santa Fe, 1723-1796. Bogotá: Imprenta Municipal.

Pérez Arbelaez, E. y Acevedo Díaz, M.(1952). Apuntamientos. Primer diario de la Expedición Botánica del Nuevo Reino de Granada por V.E. Agregado científico de ella, el cual comprende desde el día 29 de abril de 1783 hasta el día 8 de mayo de 1784. Bucaramanga: Biblioteca Santander, Vol. XXI, y en Instituto Colombiano de Cultura Hispánica (1983). Bogotá, 458 págs.

REPUBliCA ARgEnTINA. Constitución (1994). Constitución de la Nación Argentina. Buenos Aires: Kapelusz, 1994.

SAlCEDO Del VillaR, P.(1939): Apuntaciones historiales de Mompox. Cartagena, Gobernación del Departamento de Bolívar, primera edición. Santa Fe de Bogotá

SILVA FILHO, R. L. L (1997). «Minha experiência como Reitor da USP e da Universidade Mogi das Cruzes». En: Revista ADUSP, n. 9, abril 1997.

Soto ARANGO, D.(1989). Mutis: filósofo y educador. Bogotá: Universidad Pedagógica Nacional.

Soto ARANGO, D. (1994): La Ilustración en las Universidades y Colegios Mayores de Santa Fe, Quito y Caracas. Bibliografia crítica y fuentes. Bogotá: COLCIENCIAS- Universidad Pedagógica Nacional.

Soto ARANGO, D. (1988): «La Ilustración española y la reformas educativas en el Virreinato de la Nueva Granada», en Historia de la Relaciones Educativas entre España y América. V Coloquio Nacional de Historia de la Educaciòn, Sevilla, Universidad de Sevilla. pp. 57-67.

Soto ARAngO, D. (1992): Polémicas universitarias en Santafé de Bogotá. Bogotá, Universidad Pedagógica Nacional. COLCIENCIAS.

Soto ARANGO, D. y ARBOLEDA, L. C. (2003): «Introducción de una cultura newtoniana en las universidades del virreinato de la Nueva Granada» «Recepciòn y difusión de Newton en la Nueva Granada", en Recepción y difusión de textos Ilustrados. Intercambio científico entre Europa y América en la ILustración. Editores ACADÉMICOS: D. SOTO ARANGO, M. A. PUIG-SAMPER , M. BENDER Y M. D. GONZÀLEZ Ripoll. Madrid, Colecciòn La Ilustraciòn en Amèrica Colonial. Tomo III. RUdeCOlOMBIA, Universidad de Halle, ColCIENCIAS, Dirección de Investigaciones. Universidad Pedagógica y Tecnológica de Colombia. Ediciones Doce Calles, Universidad de León. 2.002.

Soto Arango, D. y ArboledA, L. C. (1995):«Los estudios de Botánica en los planes ilustrados del virreinato de la Nueva Granada», en Revista Asclepio de Historia de la Ciencia del Consejo Superior de Investigaciones Científicas, Madrid, Vol. XLVII, nº 2, 1995, pp. 113- 137 